\title{
Los habitantes de la Luna: entre la ciencia, el mito y la literatura
}

\author{
Inhabitants of the Moon: Between Science, Myth \\ and Literature
}

Carmen Fernández Galán Montemayor ORCID: 0000-0002-6926-6080 Universidad Autónoma de Zacatecas, México carmenfgalan@uaz.edu.mx

Resumen:

Este trabajo tiene como objetivo explorar las relaciones entre ciencia, ficción y mito como marcos cognoscitivos a partir de la tradición de viajes a la Luna en la literatura, así como ubicar qué mitologías han sido usadas en la descripción de la toponimia lunar. A través de un análisis comparativo, se busca explorar las estrategias de verosimilitud en relación con el mundo posible que llamamos realidad. Los escenarios y moradores de la Luna se contrastan desde una perspectiva teórica que abarca teorías de la ficción y de lo fantástico, junto con conceptos clave de la tematología e imagología comparatistas.

Palabras clave:

ficción, ciencia, mito, Luna, viaje, cognición.

Abstract:

This paper aims to explore the relationships between Science, Fiction and Myth as cognitive frameworks from the tradition of moon travel in Literature, as well as to locate which mythology has been used in the description of the lunar toponymy. 
Through a comparative analysis, this work looks to explore the plausibility strategies related to the possible world we call reality. The scenes and inhabitants of the Moon are contrasted from a theoretical perspective that includes theories of fiction and the fantastic, along key concepts of the comparative thematology and imagology.

Keywords:

Fiction, Science, Myth, Moon, Voyager, Cognition.

DOI: https://doi.org/10.36798/critlit.vi22.348

Recibido: 15 de mayo de 2020

Aceptado: 22 de noviembre de 2020

\section{Ficción, mito y ciencia}

Dentro de un mundo infinito, hay mundos infinitos... Cyrano de Bergerac

En tanto la ciencia ofrece una mirada que intenta desmantelar las verdades del mito, muchas de sus formulaciones se sostienen en constelaciones míticas, como las de la astronomía que explican el orden de las estrellas o la música de las esferas celestes. Si los mitos, como sistemas de creencias, cuando se desgastan devienen ficciones o si las mismas se vuelven realidad, la ciencia ficción es un lugar idóneo para explorar los límites difusos entre la fantasía y la realidad.

La definición de la ficción y sus límites con el mito han sido motivo de polémica desde que la ciencia positivista se postuló como explicación verdadera de las leyes de la realidad. En un universo mecanicista, la magia se transforma en la técnica y los marcos cognoscitivos que no pasan la prueba experimental dan lugar a lo maravilloso y lo fantástico como escrituras ajenas e incomprensibles para la racionalidad. En el marco de la filosofía analítica, hay una gran querella sobre la verdad de la ficción y se han intentado aclarar las preguntas implicadas en su caracterización: 1) las metafísicas, so- 
bre el tipo de existencia de los seres de ficción; 2) las de los límites de la ficción y la no ficción, como la historia, la leyenda y el mito, y 3) las convenciones o institucionalización (Pavel 24-25), esto es, la cuestión de lo que se consume o recibe como ficción. Esto último se relaciona con la configuración de los géneros literarios, los históricos y los teóricos, donde la ciencia ficción puede considerarse un género o discurso ligado a un contexto específico.

Por otra parte, las fronteras de la ciencia ficción con lo fantástico son un laberinto teórico. Para la delimitación del territorio de lo fantástico, Louis Vax agrupa la utopía junto con lo feérico, la alegoría, lo trágico y el humor, las supersticiones populares, entre otros. El mundo al revés es una de las principales estrategias de la sátira que, en el contexto de la exploración geográfica, se une a la literatura de viajes dando lugar a la utopía y las islas bienaventuradas como antecedentes de la ciencia ficción a modo de prospectivas del espacio al tiempo:

La utopía tiene algo de novela y de la experiencia mental. Es novelesca la aventura de un hombre extraviado en un mundo diferente del nuestro. . . . El lector compara con sus propios valores los de este mundo que imita al suyo. Esta descentralización nos permite distanciarnos de nuestro propio mundo... aprendemos a mirarlo desde fuera. (16-17)

En el camino de la verosimilitud y en alianza con los saberes instrumentales, el horizonte de expectativas es esencialmente un horizonte científico, resultado de un diálogo filosófico y "tal como la sátira es un posible imposible ... la utopía es un imposible posible" (Suvin 71). Ubicada dentro de lo maravilloso instrumental o científico por Todorov, la ciencia ficción, vista como los "adelantos técnicos irrealizables en la época descrita, pero después de todo, perfectamente posibles" (41), se aleja del territorio de lo fantástico y, en el contexto de la relatividad y la física cuántica, se vuelve un problema del lenguaje más que un fenómeno de percepción o un avance tecnológico (Roas 31), una narrativa que intenta asir la indeterminación entre lo real y lo sobrenatural en un mundo posmoderno e indescifrable. 
La credibilidad de la ciencia ficción tradicional tiene su base en la desviación del lector respecto a las normas de la realidad para llevarlo al experimento mental. La categoría de novum para Darko Suvin es ese puente entre lo "literario y lo extraliterario, lo ficticio y lo empírico, lo formal y lo ideológico" (95). La "verdad" de las proposiciones contenidas en los modelos de mundo oscilantes, depende de la concepción de mímesis y de realidad. Por ejemplo, en la semántica extensional de Albaladejo los mundos imaginarios se explican como mecanismos o estructuras de un conjunto referencial en relación con la realidad efectiva (84); la ciencia ficción se ubicaría en la categoría de lo ficcional verosimil en tanto las leyes que gobiernan ese modelo de mundo son el mismo universo físico-químico que habitamos.

Desde otra perspectiva y en relación con el mito, las ficciones se consideran agentes de cambio y sirven para descubrir nuevas realidades, igual que la ciencia. Sin embargo "el como si de la ficción se distingue también de la hipótesis porque no cabe duda que al final el proceso de descubrimiento será abandonado" (Kermode 47), lo que significa que la ciencia pasará a ocupar el lugar del mito y lo que percibimos como realidad es una convención culturalmente determinada, lo que Thomas Kuhn llama paradigma (84) a propósito de las revoluciones científicas.

La función de la ciencia moderna está relacionada con su capacidad predictiva y de innovación tecnológica, por lo cual uno de los principales elementos de la ciencia ficción son los aparatos, técnicas, fenómenos, experimentos y los desplazamientos espacio-temporales: el viajero o los artefactos para viajar son los elementos clave y los demás personajes se vuelven secundarios. A partir de la antropología del imaginario y las funciones del mito: ¿cuál es el significado existencial y pedagógico de los relatos de viajes interestelares?

Los entes de ficción que habitan los mundos imaginarios son para los historiadores de la ciencia ficción una forma de extrañamiento de lo cotidiano. No obstante, al revisar la historia del viaje a la Luna como tópico literario, se puede constatar que estos textos, en su mayoría satíricos, tuvieron principalmente un propósito de divulgación científica y fueron instrumentos para la comunicación de un 
conocimiento sobre la naturaleza y sobre los astros. Los conceptos de mímesis o realismo y el conocimiento extratextual determinan el tipo de objetos en estas narraciones que pueden ser nativos, cuando son creados por el autor; inmigrantes, cuando vienen del mundo real o de otro texto; o sustitutivos, que son los correlatos de ficción de objetos reales de acuerdo a la clasificación de Parsons sobre los objetos dentro de la narración de ficción (Pavel 42). En el género de la ciencia ficción, muchos de sus personajes y escenarios son tomados de la realidad en tanto otros migran de la mitología, lo que obliga a una búsqueda que en algunos casos lleva a un bloqueo referencial.

En el enfoque de una semántica mimética se torna difícil encontrar los prototipos en la realidad, por lo que debe hacerse un "rodeo interpretativo: se dice que los particulares ficcionales representan universales reales (tipos psicológicos, grupos sociales, condiciones existenciales e históricas" (Dolezel 71-72). En algunos relatos de viajes a la Luna se cumple esta condición de universalidad, y en otros en cambio se requiere una semántica de los mundos posibles para explicar las macroestructuras como constructos culturales híbridos entre el mundo natural y sobrenatural. Los mundos de la ciencia ficción son mundos naturales alternos, utópicos y especulares, y en función de la recepción de la época se conciben como sobrenaturales o normales.

\section{Atisbadores del orbe lunar}

Escribir la historia de un mito $^{1}$ es una tarea que implica la búsqueda de las fuentes de éste, que pueden ser imágenes, textos, esculturas, aunque la fuente por excelencia del mito es la literatura. A diferencia de la mayoría de los mitos, cuya primera forma de transmisión

${ }^{1}$ La historia del mito literario de la Luna en Occidente ha sido estudiada recientemente por Carlos García Gual (2005), Alfonso Alcalde-Diosdado Gómez (2011) y Peter Gutjarhd (2018), entre otros. En este artículo no se siguió un criterio cronológico, sino más bien temático para explicar las relaciones entre ciencia, mito y literatura. 
es oral, los mitos relacionados con la Luna nacieron en la literatura, lo que otorga un estatus distinto a los relatos resultado de la especulación de lo que puede ser el escenario lunar y qué formas de vida existen ahí. En ese sentido, los personajes "surgen de la mente de un autor, es decir, un inventor" (Carriére 34) y aparecen en fórmulas literarias específicas. El siguiente es un recorrido por algunas de esas fuentes literarias del mito $^{2}$ para identificar los elementos comunes, la migración de personajes, la visión de mundo y la ciencia o saberes atendiendo a su contexto y, sobre todo, para tratar de encontrar quiénes son los habitantes de la Luna.

$\mathrm{Al}$ parecer la historia del viaje a la Luna comienza en un diálogo filosófico de Plutarco en el siglo I titulado Sobre la cara visible de la Luna, donde se discute sobre la posibilidad de vida en la Luna conforme a su naturaleza y esencia: tierra, fuego o aire, sus movimientos y eclipses. Los rayos de luz dejan ver en esa cara visible manchas negras que se interpretan como océanos, istmos y continentes. A través de cálculos matemáticos sobre la distancia de los astros y los objetos en la Tierra, se llega a la conjetura de que la realidad tiene invertida su posición respecto del arriba y el abajo, y si se pudiera armonizar el centro de la Tierra con su ombligo, es decir, equipararla con el cuerpo humano, se tendrían cabeza y pies hacia arriba. El Sol aporta su brillo a la Luna, y sin él, no habría cara oscura.

En el diálogo de Plutarco se formula la mitología que será retomada en otros viajes lunares sobre la esencia del hombre que está compuesta de cuerpo, alma e intelecto, que corresponden a la Tierra, Luna y Sol, respectivamente. Por ello, cuando un hombre muere, su alma va a la Luna donde atraviesa distintas etapas hasta convertirse en un daimon que participa en asuntos terrestres, figura que aparecerá en relatos posteriores. En este caso los habitantes de la Luna son las almas de los muertos.

${ }^{2}$ Para una revisión exhaustiva de las fuentes del mito véase: Alcalde-Diosdado Gómez, Alfonso. El tópico del hombre en la Luna en las literaturas cultas y populares. 2002. Universidad de Granada, Tesis doctoral, pp. 35-49. En esta tesis se incluye una lista de 275 textos de todos los géneros literarios. 
A diferencia del viaje a la Luna de Julio Verne, que surge en el contexto de las sociedades industriales a manera de predicción de la conquista espacial, las primeras manifestaciones literarias del tópico de viajes fueron instrumentos de desmitificación, como es el caso de Luciano de Samosata en Historia verdadera (siglo II), una sátira que parodia tanto a personajes mitológicos como legendarios: desde los grandes historiadores y filósofos como Heródoto, Tucídides y Platón, hasta Neptuno, Minerva, Áyax y Circe. En uno de sus viajes el protagonista llega a la Luna porque su barco fue elevado por los aires a causa de una tormenta de siete días. El escenario lunar es un mundo al revés donde los hombres dan a luz, los "arbóreos"3 y los lunares son criaturas extrañas que tienen ojos móviles, comen ranas, sudan suero que produce queso, utilizan su vientre como bolsa y no tienen ano, los ricos visten de cristal y los pobres de bronce (Samosata 192). Retrato muy peculiar de los habitantes de la Luna, que solo se trata de una estrategia satírica para representar al otro, al extranjero, así como para poner en duda las verdades del conocimiento.

Será hasta 1505 que se retome el tema del viaje a la Luna en el canto XXXIV de Orlando Furioso de Ludovico Ariosto, donde el personaje llega en un carro de fuego que había servido a Elías y comprueba que la Luna es un mundo como el nuestro: hay ríos, lagos, llanuras y ciudades (García Gual, Viajes a la Luna 256), solo que se invierten las funciones del arriba y el abajo, como en un mundo al revés. Algunos de estos personajes migrarán hasta el siglo XX, como en el poema "La Luna" de Borges: "Ariosto me enseñó que en la dudosa Luna moran los sueños, lo inasible, el tiempo que se pierde, lo posible o lo imposible, que es la misma cosa" (Pérez ); y en la "Historia de Astolfo en la Luna" de Italo Calvino, en la que el personaje es representado con la baraja del Caballero de Bastos que sube en el arcano del tarot El carro a la Luna, y si no logra ofrecer una visión detallada del mundo al revés, pone en voz de un habitante de la Luna, que es la carta de El Presdigitador, al poeta, quien dice

${ }^{3}$ Los hiperbóreos son los habitantes de distintos hemisferios separados por el mar, según López de Gómara, en su Historia General de las Indias. 
que los blancos campos de la Luna son un horizonte vacío (El castillo 54-55). Astolfo es el prototipo del viajero observador y en este caso un personaje que viaja de un texto a otro en siglos de distancia:

explorador lunar que jamás se maravilla de nada, que vive circundado por lo maravilloso y se vale de objetos embrujados, libros mágicos, metamorfosis y caballos alados con la liviandad de una mariposa, pero siempre para lograr fines de utilidad práctica y totalmente racionales. (24)

En el lado opuesto a la poesía, la astronomía lunar es descrita por Kepler en Somnium, publicación póstuma de 1634, que es considerada una novela de ciencia ficción, sin embargo, es una carta donde la geometría de Levania se narra en un diálogo del protagonista con Tycho Brahe, que junto a sombras y daimons, ${ }^{4}$ son los guías del viaje. Los habitantes de la Luna tienen los gentilicios de sus hemisferios: Subvolva y Privolva, que son quizá los hemisferios terrestres puesto que la Tierra es llamada Volva. Una de las ocupaciones de los habitantes de Levania es la contemplación de la Tierra como nosotros contemplamos la Luna. Ciertamente, el momento en que Kepler escribe es de observación astronómica. En 1609, Galileo ya había dibujado los mares, montañas y cráteres lunares. El "sueño" de Kepler se ubica justo en medio del primer mapa lunar de 1611, que se atribuye a Thomas Harriot, y de la toponimia o Selenografía de Grimaldi, Langrenio, Hevelius y Riccioli, entre los años de 1640 y 1651. El formato de carta y el diálogo filosófico son una forma de transmisión del conocimiento, por lo tanto, entre alusiones míticas, las referencias extratextuales son a una realidad efectiva.

Las probabilidades de realizar un viaje a la Luna y la habitabilidad de esta son el argumento de El descubrimiento de un nuevo mundo en la Luna (1638) de John Wilkins. Conjetura y verosimilitud de lo que pudieran ser los habitadores de la Luna, el autor se pregunta

${ }^{4}$ La palabra daimon significa 'espíritu'. En Hesíodo son las almas de los muertos que cuidan a los mortales. Aparecen en el diálogo filosófico de Plutarco. 
si proceden de la estirpe de Adán y merecen salvación; citando a Nicolás de Cusa afirma que, como aquella región es desconocida totalmente, igual lo son sus habitantes "ha sido creencia común entre los antiguos el que sus cielos y Campos Elíseos estén en la Luna, donde el aire es más sosegado y puro" (Wilkins 89). El texto es una disertación científica, teológica y matemática que toma como fuentes a Plutarco y San Agustín, y hasta a Kepler, Campanella y Bacon.

El mismo año de la obra de Wilkins, se publica las Aventuras de Domingo González en su extraño viaje al mundo lunar de Frances Godwin, donde aparecen varios cálculos sobre los requisitos para trasladarse a la Luna, la distancia de la Tierra con respecto a esta y el problema de la gravedad. Además, se predice que algún día los hombres podrán volar de un sitio a otro y enviarán mensajes a cientos de millas de distancia. En la Luna las cosas son "diez, veinte o treinta veces más grandes que las nuestras" y los habitantes "con apariencia y modos completamente distintos a los nuestros, de estatura muy diferente, del orden de dos o tres veces mayores que nosotros" (Godwin 66-67), aunque sí hay hombres de talla pequeña más parecidos a los humanos. Se citan como relatos lunares obras de carácter histórico como la Descripción de Nueva Granada de Iñigo Mondéjar y la Historia de México de José Desia de Carana. En esta narración son distinguibles personajes históricos que pasan al terreno de la "ficción".

Bajo la perspectiva de Cyrano de Bergerac, la Tierra igualmente es una Luna: "Historia cómica de los Estados e imperios de la Luna" de 1657 es la primera parte de la obra El otro mundo, que tiene como argumento central una supuesta retractación de Galileo por decir que la Luna es "Otro Mundo" (29). La Luna es el Edén y ahí está Elías, quien cuenta cómo llegaron Acab y Enoc. Los habitantes son más grandes que los hombres de la Tierra, todo es al revés en cuanto a concepción del tiempo, espacio y rituales: los habitantes se expresan con sonidos musicales y comen humo, hay ciudades móviles y libros parlantes. Es un espejo para ver los errores de este mundo.

El tema de la trasmigración de las almas reaparece en Viage de el mundo de Des-Cartes, publicado en 1690, del jesuita Gabriel Daniel, un viaje que se realiza durmiendo para visitar a los habitantes de 
la Luna que son almas (72). El escenario lunar es muy complejo: hay un Liceo de Filósofos y la cartografía lunar se basa en los mapamundis de Grimaldi y Luria; ${ }^{5}$ las disertaciones giran en torno a la toponimia relacionada con Platón y Aristóteles para refutar a los peripatéticos y a Descartes, Tycho Bryhe, Gassendi, Magnain y el mencionado Cyrano de Bergerac. Esta obra pertenece al género literario del diálogo filosófico, entremezclando autores y sus entelequias. La estrategia del sueño o visión es un tópico recurrente en el Barroco y durante la revolución científica fue un recurso que llevó a la realización de experimentos mentales que sustentaron teorías científicas, como en el novum de Suvin.

Durante el siglo XVIII hubo un incremento de la literatura de viajes y exploraciones a todos los continentes. Según García Gual: "En esta época nacen la antropología y la mitología comparada" (Viajes novelescos 96). Es la transición del pensamiento barroco al ilustrado. En 1703 se publica en Londres Iter lunare or a vogage to the moon de David Russen, que tendrá una gran influencia de Bergerac Plutarco, Wilkins, Descartes, Cardano (comunicación invisible) y

${ }^{5}$ El primer mapa de la Luna con observación telescópica lo realizó Galileo, c. 1610. Posteriormente aparece el mapa de Claudio Mellan en 1636. En 1645, Scheiner y Rheita publicaron otros mapas lunares; ese mismo año Langrenus editó un mapa en el que distinguía tres tipos de accidentes: reconoció las manchas oscuras como "mares", las claras como "tierras" y los hoyos circulares como "circos", denominaciones que hoy persisten. En 1647, Hevelius desarrolló un mapa en que catalogaba unos 250 accidentes lunares que bautizó con analogías terrestres. El mapa basado en observaciones de Grimaldi fue publicado por Riccioli en 1651, ahí aparecen nuevas nomenclaturas basadas en personajes ilustres. La Selenografía se retoma hasta 1775 con Schroter, en el observatorio de Lilienthal, quien usó los telescopios de Herschel. En Der Mond de 1837, Madler y Beer conservan la nomenclatura tradicional. Pioneros en la introducción de la fotografía en el estudio de la Luna, Nasmyth y Carpenter publicaron en 1874 The Moon, en 1876 apareció con el mismo título una obra de Edmund Neison y en 1878 aparece el mapa del astrónomo Schmidt. En el siglo XX la historia es distinta, cuando en 1959 las sondas espaciales de los soviéticos impactaron en el Mar de la tranquilidad (Cfr. Monje 40 y ss). En el siglo XIX, Krutohlav se interesó en describir la Selenografía en su novela publicada por episodios (Alcalde-Diosdado 261). 
Campanella. Con una estructura de diálogo, se tratan las formas de gobierno, la forma del orbe lunar y las posibilidades de ascender, como Domingo González al Tenerife. Esta obra marca una diferencia sustancial con las anteriores en dos aspectos: deja atrás el tono satírico y utiliza un lenguaje cifrado para transmitir saberes prohibidos en ese momento. Es posible identificar muchas referencias alquímicas, neoplatónicas, geográficas, matemáticas, entre otras. En esta línea, que podemos denominar científica, Diego Torres Villarroel toma como modelo Itinerarium extaticum y Mundus subterraneus del jesuita alemán Athanasius Kircher $^{6}$ para escribir Viaje fantástico del gran Piscator de Salamanca. Jornadas por uno y otro mundo descubrimiento de sus sustancias, generaciones y producciones en 1724. Este viaje trata de cálculos sobre eclipses y presenta una discusión en torno a pronósticos y los efectos de los fenómenos celestes. Como la mayoría de obras dieciochescas, se encuentra en la frontera de la astrología judiciaria que se convertirá en astronomía.

De circulación clandestina y motivo de un proceso inquisitorial en México, Syzigias y quadraturas lunares... de Manuel Antonio de Rivas es una carta y un almanaque de 1775. Se describe un Ateneo lunar donde los anctítonas ${ }^{7} \mathrm{o}$ habitadores de la Luna revisan cálculos astronómicos y sistemas de calendarización. El viajero francés llega por ascenso de turbillón ${ }^{8}$ en un carro o bajel volando. Cuando arriba al orbe, le dan indicaciones de recorrer tres regiones: el Monte de la Plata, el País de los sordos y el Puente de los asnos.' Los habitantes de la Luna se encuentran en la región de Platón (ya nombrado así uno de sus cráteres en la Selenografía) o país de las

${ }^{6}$ Cuyo nombre se conserva aún para un cráter en la Selenografía. La obra Iter extaticum coeleste es un viaje por el sistema solar (Alcalde-Diosdado 186).

${ }^{7}$ Probablemente se refiera a los antípodas, denominación antigua usada para quienes habitan en el hemisferio opuesto del orbe terrestre (DRAE).

${ }^{8}$ Es un término de la física dieciochesca que tiene su origen en la teoría del Universo de Descartes sobre los torbellinos y el movimiento de los cuerpos celestes (Corpus diacrónico español).

9 "Allí, en aquellas vastas llanuras, se debían trazar inmensas figuras geométricas, dibujadas por medio de reflectores luminosos, entre otras el cuadrado de la hipotenusa, llamado vulgarmente en Francia el puente de los asnos" (Verne 22). 
Quimeras. Hay otras referencias a personajes reales o sustitutivos como Newton, Duhalde y Desforgues, un canónigo francés que construyó un carro volante y se lanzó de una torre al sur de París. La idea de colocar el Paraíso en la Luna y el Infierno en el Sol, en el relato de Rivas, está tomada de la obra de Tobías Swinden o Suvirnethon titulada An enquiry into the Nature and Place of hell, que estaba en el Índice de libros probibidos de la Inquisición. Estas obras pasaron desapercibidas a los calificadores que: "asumen como real lo imaginado por el fraile y discuten si es verdad o mentira que el infierno está en el Sol, que existan dos infiernos y si los astros y el ambiente influyen en el temperamento de las personas" (Depetris 15). La defensa en el proceso inquisitorial utilizará un argumento copernicano sobre la relatividad del arriba y del abajo resultado de los movimientos celestes. Syzigias y quadraturas lunares está escrito además en un lenguaje alquímico encriptado.

Las aventuras del Barón Münchausen, publicada en 1793, de Rudolph Erich Raspe recupera tradiciones populares emulando la estructura argumental de Samosata en dos modos de llegar a la Luna (Alcalde-Diosdado 239), cuyos habitantes son gigantes, por lo que no tiene muchos elementos científicos, en tanto la descripción de los selenitas es extravagente igual que en la Historia verdadera. En cambio, la Luna es de nuevo el país de las almas en el Viaje estático al mundo planetario del jesuita Lorenzo Hervás y Panduro publicada en 1793. Ahí Cáncer y Capricornio son las puertas del cielo por donde bajan las almas. El autor recupera la tradición pitagórica de que en la Luna los animales son quince veces mayores. Presenta la observación de los cielos con telescopio en oposición a la mitología pagana que alaba los astros como dioses. Invita al lector a volar con la mente para explicar las leyes del movimiento de los cuerpos celestes y las relaciones entre los fenómenos de óptica y geometría. En esta obra, los lunícolas envían espías a la Tierra para ver las razas y vestimentas de los terrícolas (Hervás 130). Se habla también de un viajero español que dejó un libro en muchos idiomas.

El Viaje de un filósofo a Selenópolis. Corte desconocida de los habitantes de la Tierra, publicado en 1804, de Antonio Marqués y Espejo está basada en una obra de 1761 atribuida a Daniel de Villeneuve: Le 
voyageur philosophe dans un pais inconnu aux habitants de la Terre, que apareció en Amsterdam bajo el pseudónimo de Mr. De Listonai. En esta obra, la Luna se rige bajo las mismas leyes que la Tierra, por lo que sus habitantes tienen las mismas costumbres:

hay algo en el Viage de un filósofo que llama poderosamente la atención: la original combinación de viaje a la luna y viaje a los antípodas, con el consiguiente paralelismo entre las dos caras de la Luna y los dos mundos de nuestra Tierra: el mundo «civilizado» occidental, sumido en maldades y corrupciones, es Europa, y tiene su correlato en la cara visible de la Luna; pero hay otro mundo diametralmente opuesto a él, un mundo feliz y perfecto, que está situado al otro lado del inmenso océano: en nuestro planeta sería América, la tierra de promisión, pero de lo que aquí se nos habla es de la América de la Luna, allá en su otra cara oculta e invisible: Selenópolis. (Álvarez 44-45)

Las maneras de llegar a la Luna que eran carros o barcos se vuelven máquinas (globos, cohetes) en el siglo XIX, como será el caso de George Tucker, de Edgar Allan Poe y por supuesto de Verne. En $A$ Voyage to the Moon: with some account of the manners and customs, science and philosophy of the people of Morosofia and other Lunarians de 1827, Tucker dedica un apartado especial a los inventos mecánicos; semejante a la utopía en ninguna parte o imposible de ubicar, Erewhom, de Samuel Butler, tiene un apartado titulado "Libro de las máquinas" a las que clasifica por géneros, especies, suponiendo que son una forma de vida que se reproduce en virtud de que hay máquinas que fabrican máquinas y que por lo tanto tienen algún tipo de conciencia (201 y ss). En lo que corresponde a los habitantes de la Luna, Tucker describe sus formas de gobierno y religión a través del personaje Artteley, nacido en Long Island en 1786.

Las analogías del mundo lunar y el terrestre se encuentran de igual modo en La incomparable aventura de un tal Hans Pfall de Edgar Allan Poe, quien deja ver que el principal obstáculo para viajar a la Luna es el dinero. El protagonista escribe en su diario las eventualidades del viaje en globo y narra en una ensoñación un paisaje lunar 
de quimeras, cataratas y lagos oscuros, riscos, abismos y campos flégreos. En su carta, Pfall dice respecto a los selenitas:

de sus maneras, de sus costumbres e instituciones políticas, de su peculiar constitución física, de su fealdad, de su falta de orejas, apéndices inútiles en una atmósfera a tal punto modificada; de su consiguiente ignorancia del uso y las propiedades del lenguaje; de sus ingeniosos medios de intercomunicación, que lo reemplazan; de la incomprensible conexión de cada individuo de la Luna con algún individuo de la Tierra, conexión análoga y sometida a las esferas del planeta y el satélite. (56)

La tradición de viajes imaginarios es retomada en De la Tierra a la Luna (1865) y Alrededor de la Luna (1869). Julio Verne menciona como pioneros de esta tradición a David Fabricius y a Jean Baudoin, a los que considera autores del viaje de Domingo González de 1649 (atribuido a Godwin), junto con Edgar Allan Poe, Cyrano de Bergerac y Fontenelle, quien escribió la Pluralidad de los mundos y quien fue parodiado por Voltaire en el cuento filosófico Micromegas de 1752; incluye además un opúsculo de 1835 de John Herschell (Verne 21), hijo del astrónomo William Herschell, quien fabricó un telescopio que le permitió descubrir el planeta Urano en el año de 1781. Mucho se ha escrito sobre la obra de Verne y sus predicciones del alunizaje de 1969. Siguiendo la reflexión de la historia de este tópico, todos los autores usan el conocimiento de su época en la creación de las posibilidades, por lo que podríamos considerar estos textos como ensayos o escritos de carácter científico.

La historia de la ciencia ficción ${ }^{10}$ y los vuelos interestelares en el siglo XX comienza con The First Men in the Moon en 1901 con H. G. Wells. Los selenitas son parte de una compleja y sofisticada sociedad tecnológica que vive bajo tierra y existen en miles de formas que encuentran significado a partir de una función social específica. Es una

${ }^{10}$ Hay un boom de la ciencia ficción en el siglo Xx, considerada paraliteratura por estar dirigida a las masas, lo que llevará al Pulp fiction (Cano 22). 
utopía marxista en la que vuelve a aparecer la cuestión de la sombra o cara oculta de la Luna. Muy distinta es la visión de Italo Calvino, que recupera el humor de las sátiras de la primera tradición en las Cosmicómicas de 1963, con la hipótesis de que la Luna estaba muy cerca de la Tierra en "La distancia de la Luna" y que los continentes terrestres son fragmentos de la Luna en "La blanda Luna" (149), para ofrecer una versión literaria de las teorías de la física cuántica.

En formato de cuento corto, Arthur C. Clarke publicó El centinela en 1951, que trata de un artefacto abandonado en la Luna por los alienígenas, obra que inspiró cine de ciencia ficción de Stanley Kubrick, igual que las de Verne y Welles. En 1902, Le Voyage dans la Lune de Georges Méliès crea una nueva mitología lunar junto con el televisado alunizaje de 1969, que hizo a los terrícolas los habitantes de la Luna, es decir, los selenitas. A partir de esta fecha, la literatura sobre viajes a la Luna será protagonizada por los astronautas y sus biografías, con lo que ingresa en un ámbito supuestamente "científico": el mito entra en la zona de la realidad y se acepta como verdad. Sin embargo, en 2002, William Karel hace un falso documental titulado Operation Lune. Dark side of the Moon (alusión al disco homónimo de Pink Floyd), que vuelve a poner el mito en la zona de la ficción argumentando que el alunizaje de 1969 es news making. La teoría de las conspiraciones y las fake news suscitan un gran debate a la fecha. De esta forma el mito pasó de la literatura a la televisión, de la televisión al cine, ${ }^{11}$ del cine a los videojuegos y de la realidad simulada al turismo espacial. ${ }^{12}$

${ }^{11}$ Después del alunizaje aparecerán varios filmes que oscilan entre la ciencia ficción, el documental y la sátira: El Conquistador de la Luna (1960) de Raúl Martínez Solares, First Men on the Moon (1964) de Nathan Juran, 2001: A Space Odyssey (1968) de Stanley Kubrick, The Right Stuff (1983) de Philip Kaufman, el documental For All Mankind (1989) de Al Reinert, el stop motion A Grand Day Out (1989) de Nick Park, Apollo 13 (1995) de Ron Howard, Austin Powers: The Spy Who Shagged Me (1999) de Jay Roach, The Dish (2000) de Rob Sitch, el falso documental Opération Lune (2002), Moon (2009) de Duncan Jones, el documental Last Man on the Moon (2014) de Mark Craige, First Man (2018) de Damien Chazelle.

${ }^{12}$ Como es el caso de la iniciativa Misión SpaceX de Tesla y la NASA. 
La historia del viaje a la Luna en la literatura está aún por completarse, y como se observa en este recuento es el siglo XVIII el de mayor auge, los autores son españoles o franceses principalmente, en tanto que en el siglo XIX aparecen ya autores americanos. En el esfuerzo por completar la lista de obras, se incluyó aquí el cuadernillo Syzigias y quadraturas lunares... escrito en México durante el siglo XVIII y que fuera rescatado en la década de los ochenta. ${ }^{13}$ La viabilidad de integrar todos los testimonios dentro del género de la ciencia ficción implica el reconocimiento del hibridismo y las fronteras con la sátira y el diálogo filosófico. El común denominador de esta literatura es el contenido científico en frontera con el sueño o visión: "para que exista lo fantástico, tiene que aparecer, manifiestamente a veces, críptica otras, el testimonio de que se están confrontando dos concepciones de mundo" (Morales 10). Todos los relatos podrían calificarse de fantásticos ${ }^{14}$ y aquí radica su valor, en tanto que llevan a la experiencia de los límites: entre la realidad y la ficción, entre el mito y la historia, entre los terrícolas y los selenitas.

\section{Conclusiones}

En este inventario de viajes y selenitas se advierte que la verosimilitud y marco cognoscitivo van de la mano en la construcción de proyectos científicos y mundos posibles. Lo que hoy se consume como ficción fueron textos que usaron estrategias literarias en la

13 Véase al respecto: La literatura perseguida en la crisis de la Colonia (1983) de Pablo González Casanova, Esplendores y miserias de los criollos (1995) de José Joaquín Blanco y el primer rescate de la obra de Ana María Morales en la revista del INAH en 1992. En sus Antologías del relato fantástico mexicano (2008), Morales ha construido una tradición mexicana de literatura de la imaginación. Hay posteriores ediciones del relato de Rivas en 2009 y 2010, por la UNAM y por Factoría-UAZ, respectivamente.

${ }^{14}$ O utópicos desde otra perspectiva. Véase: Castagnino, María Inés, et al., compiladores. Textos utópicos en la Inglaterra del siglo XVII Tomo II: Viajes a la Luna, utopías selenitas y legado científico. Universidad de Buenos Aires, 2014. 
construcción de un conocimiento, y como dice Italo Calvino: "El amor por la luna, se desdobla en amor por su reflejo, como subrayando en la luz reflejada la vocación por los juegos de espejos" " $\mathrm{La}$ luna corre tras la Luna" 203), es decir, el conocimiento de sí mismo. En la historia de la ciencia occidental hay un episodio clave durante el iluminismo que significó el cambio en la manera de transmitir los saberes de un lenguaje que antes era cifrado y para iniciados, que se tornó claro y universal como ocurre en la literatura del siglo XIX. De modo que el lenguaje de los relatos de viajeros interestelares que hoy se interpreta como fantasía, era en su contexto lenguaje hermético, escrito en clave para iniciados o para poder transmitir saberes considerados heterodoxos. En todos los relatos se debaten tópicos científicos y sus implicaciones en la cosmogonía, resultado de la observación de los fenómenos celestes.

Desde la teoría de la ficción se postula la infinitud de los mundos posibles que están formados por amasijos de universos igualmente (Pavel 68). Las ficciones consisten en una multiplicidad de mundos actuales en un sistema y esa estructura dual de universos primarios y secundarios o salientes explican los constantes saltos de la imaginación a la realidad en los relatos interestelares que utilizan referencias al universo factual; los escenarios o personajes de ficción son alusiones al mundo real, a términos científicos (alquimia, física y astronomía), a océanos, continentes y montañas. En ocasiones este principio de dispersión hace que las frases del texto remitan a otros libros en rutas intertextuales y, como se ha visto, los personajes reales y ficticios, igual que sus autores, migran de un texto a otro. Siguiendo la tesis en lógica modal de que todos los mundos posibles junto con los objetos que los pueblan son tan reales como este mundo (Pavel 65), se confirma que la metáfora de la máquina y del reloj de las teorías mecanicistas, así como muchas de las estrategias empleadas en los relatos, son efectivamente leyes científicas (Shapin 51) y las consecuencias de la observación astronómica y de la relatividad de lo que está arriba y está abajo son una cuestión de método: 
Lo normal en astronomía es obtener imágenes invertidas (de norte a sur y de este a oeste), ya que la mayoría de los telescopios astronómicos carecen de sistemas inversores, que restarían luminosidad a la imagen. La imagen invertida no conlleva problemas cuando lo que tenemos en el campo son estrellas, pues no tenemos noción de su disco y no nos interesa saber dónde se encuentran sus coordenadas de latitud y longitud. Para el caso de planetas o la propia Luna, las dificultades quedan patentes. (Monje 9-10)

Estas implicaciones de la observación astronómica en las teorías del universo y la concepción de la realidad fueron advertidas por todos los autores de viajes lunares. En ocasiones los viajes fantásticos fueron un correlato de los viajes terrestres en un proyecto de expansión territorial que impulsó la navegación y los mapas celestes como sus herramientas. Para la determinación de las longitudes terrestres se usó la topografía lunar durante los eclipses de 1736 y 1740 que están en las cartas de Jorge Juan y Ulloa, que ocupan un lugar destacado en la historia de la cartografía lunar (Catalán 111). La medida de la figura de la Tierra está en las sombras, en la cara oculta de la Luna: "La ciencia operó como un lujoso y multifacetado espejo sobre el cual Europa toda podía reflejarse como un proceso planetario en expansión” (Pratt 77). Así, el impacto del conocimiento científico en la geopolítica es indiscutible.

La experiencia libertina y filosófica del siglo XVIII fue más allá al "encontrar vinculaciones entre los procedimientos formales y retóricos usados en la producción de textos literarios ... y los procedimientos filosóficos y epistemológicos" (Ceserani 137). Existe una estrecha conexión entre ciencia y literatura en la nueva cosmogonía donde se interrelacionan tres niveles de conocimiento: cósmico, religioso y político (Ginzburg 103). La ciencia ficción lunar tiene su correlato terrestre en la forma de reordenar la geografía y los marcos cognitivos resultado del hallazgo de otras culturas.

En este comparativo de los escenarios lunares se perciben las renovaciones de los mitos y la transmutación de los valores. De esta manera, las constelaciones míticas se van enlazando: los profetas 
Elías y Enoc, así como los Campos Elíseos, a Ícaro, Prometeo y Faetón como representantes de la curiosidad intelectual y de un saber producido por astrónomos, filósofos y herejes son analogías subversivas derivadas de la exploración celeste. La cuenca semánti$\mathrm{Ca}^{15} \mathrm{o}$ de mayor auge del mito se encuentra en los siglos XVIII y XX, en momentos históricos en que se da un cisma entre verdades de fe y de conocimiento. Los motivos redundantes o mitemas ${ }^{16}$ son: el viaje y el encuentro con los otros, lo que los tipifica como mitos de ascensión y de régimen predominante diurno, pues los protagonistas de los viajes son héroes civilizadores y/o colonizadores.

Del sustrato del mito en sus transformaciones literarias, permanecerán solamente los países de las Quimeras y Platón de aquella Selenografía que dividió la topografía lunar en mares, lagos, bahías, lagunas, y cráteres. Así como se hicieron atlas de la Luna, "los modelos de mundo son mapas de la realidad, no la realidad en sî" (Schmidt 215), el estatus de verdad depende de convenciones y reglas que determinan que algo se experimente como real o como ficticio. Para establecer la relación alterna de un mundo con otro, se necesita un criterio que puede ser la identidad de los individuos que pueblan esos mundos posibles que a veces resultan ser el mismo: "No es otro el universo que se encuentra frente al nuestro; es nuestro propio mundo que, paradójicamente, se metamorfosea, se corrompe y se transforma en otro" (Vax 17). ¿Cuál es la diferencia entre un selenita y un terrícola, o cuál es la diferencia entre un quark y un ente de ficción? Nadie ha demostrado su existencia, pero son necesarios para la teoría y para explicar la realidad, igual que los

15 "Una cuenca semántica es una estructura — con todo el sentido de dinamicidad que el estructuralismo figurativo le da a este término- sociocultural, identificada por regímenes específicos de la imagen y mitos dominantes — que le dan nombre y la tipifican-, que corresponde a un contorno común, delimitado por una época, un estilo, una estética, una sensibilidad, en definitiva, una visión y, por lo tanto, una expresión del mundo, compartidos.” (Gutiérrez 187).

${ }^{16} \mathrm{El}$ mitema se define como "pequeño denominador común de sentido simbólico, es una corta secuencia que funciona como unidad autónoma y, al mismo tiempo, vinculada a un sistema mítico más vasto" (Monneyron y Thomas 54). 
mitos. El lado oscuro de la Luna, como mundo al revés, es la posibilidad del conocimiento del Otro y el espejo de las utopías.

\section{Bibliografía}

Alcalde-Diosdado Gómez, Alfonso. El hombre en la Luna en la Literatura. Universidad de Granada, 2011.

Álvarez de Miranda, Pedro. "El Viage de un filósofo a Selenópolis (1804) y su fuente francesa". Actas XIV Congreso AIH, vol. III, 15 octubre 2019, pp. 43-51, cvc.cervantes.es/literatura/aih/ pdf/14/aih_14_3_006.pdf

Ariosto, Ludovico. Orlando furioso. Traducción de José María Mico, Austral, 2017.

Bergerac, Cyrano. El otro mundo. Traducción de Carlos Bonfil, Conaculta, 1992.

Butler, Samuel. Erewhom. Traducción de Ogier Petrecielle, Ediciones Minotauro, 2000.

Calvino, Italo. El castillo de los destinos cruqados. Traducción de Aurora Bernárdez, Siruela, 2004.

. "La distancia de la Luna", Todas las cosmicómicas. Traducción de Ángel Sánchez-Gijón, Siruela, 2002, pp. 13-26.

"La luna corre tras la Luna", Colección de arena. Traducción de Aurora Bernárdez, Siruela, 2002, pp. 203-204.

. Orlando furioso narrado en prosa del poema de Ludovico Ariosto. Traducción de Aurora Bernárdez y Mario Muchnik, Siruela, 2014.

Carriére, Jean-Claude. "Juventud de los mitos", compilado por Bernadette Bricout, La mirada de Orfeo, traducción de Gemma Andújar Moreno, Paidós, 2002, pp. 25-46.

Cano, Luis C. Intermitente recurrencia. La ciencia ficción y el canon literario hispanoamericano, Corregidor, Buenos Aires, 2006.

Castagnino, María Inés, et al., compiladores. Textos utópicos en la Inglaterra del siglo XVII Tomo II: Viajes a la Luna, utopías selenitas y legado científico. Universidad de Buenos Aires, 2014.

Catalán Pérez-Urquiola, Manuel. "El viaje a la América ecuatorial para la medida del arco meridiano". Literatura de viajes. El Viejo 
Mundo y el Nuevo, coordinado por Salvador García Castañeda, Castalia, 1999, pp. 105-114.

Ceserani, Reno. Lo fantástico. Traducción de Juan Díaz de Atari, Visor, 1999.

Daniel, Gabriel. Viage de el mundo de Des-Cartes. Editado por Luis Villoro, Universidad de Guanajuato, 1996.

Dolezel, Lubomir. "Mímesis y mundos posibles". Teorías de la ficción literaria, compilado por Antonio Garrido Domínguez, Arco Libros, 1997, pp. 69-94.

García Gual, Carlos. "Viajes novelescos y novelas de viajes a fines del siglo XVIII". Literatura de viajes. El Viejo Mundo y el Nuevo", coordinado por Salvador García Castañeda, Castalia, 1999, pp. 95-104.

. Viajes a la Luna. De la fantasía a la ciencia ficción. ELR Ediciones, 2005.

Ginzburg, Carlo. Mitos, emblemas, indicios. Morfología e historia. Traducción de Carlos Catroppi, Gedisa, 1999.

Godwin, Frances. "Aventuras de Domingo González en su extraño viaje al mundo lunar". Viajes a la Luna. De la fantasía a la ciencia ficción, de Carlos García Gual, ELR Ediciones, 2005, pp. 49-81.

Gutiérrez, Fátima "La mitocrítica de Gilbert Durand. Teoría fundadora y recorridos metodológicos". Théléme Revista Complutense de Estudios franceses, vol. 27, 2012, 175-189.

Gutjarhd, Peter. Voyage to the Moon' and Other Imaginary Lunar Flights of Fancy in Antebellum America. Editado por Robert Douglas-Fairhurst, Anthem Prees, 2018.

Hervás y Panduro, Lorenzo. Viaje estático al mundo planetario. Imprenta de Aznar, 1793, www.cervantesvirtual.com/obra/viaje-estatico -al-mundo-planetario-en-el-que-se-observan-el-mecanismo-ylos-principales-fenomenos-del-cielo-se-indagan-las-causas-fisicas-y-se-demuestran-la-existencia-de-dios-y-sus-admirablesatributos-tomo-2-parte-1-sigue-la-parte-primera--0/

López de Gómara, Francisco. Historia General de las Indias. Biblioteca Ayacucho, 1978, www.cervantesvirtual.com/obra-visor/ historia-general-de-las-indias--0/html/ . 
Monje, Juan Carlos. Selenografía para telescopios de aficionados, Sirius, 1991, docplayer.es/45810977-Julio-cesar-monje-la-luna-selenografia-para-telescopios-de-aficionados.html_

Monneyron Frédéric y Jöel Thomas. Mitos y literatura. Traducción de Emilio Bernini, Ediciones Nueva Visión, 2004.

Morales, Ana María. México fantástico. Antología del relato fantástico mexicano. Fondo Nacional para la Cultura y las Artes / Consejo Nacional para la Cultura y las Artes, 2008.

Kepler. Somnium. Traducción de Normand Raymond Falardeau, Frosty Drew Observatory and Science Center, frostydrew.org/ papers.dc/papers/paper-somnium/

Kermode, Frank. El sentido de un final. Estudios sobre la teoría de la ficción. Traducción de Lucrecia Moreno de Sáenz, Gedisa, 2000.

Kuhn, Thomas. La estructura de las revoluciones cientificas. Traducción de Carlos Solis, Fondo de Cultura Económica, 1971.

Pavel, Thomas. Mundos de ficción. Traducción de Julieta Fombona, Monte Ávila, 1991.

Pérez Parejo, Ramón. “Metapoesía y ficción en 'La luna' de Borges". Especulo, no. 30, 2005, webs.ucm.es/info/especulo/numero30/index.html

Plutarco. "Sobre la cara visible de la Luna". Moralia, Traducción de Vicente Ramón Palerm y Jorge Berua Cabrero, Gredos, 2002, archive.org/stream/MORALIA09CSobreLaCaraVisibleDeLaLuna./MORALIA $\% 2009 \% 20$ c $\% 20-\% 20$ Sobre $\% 201 \mathrm{a} \% 20$ cara $\% 20$ visible $\% 20 \mathrm{de} \% 201 \mathrm{a} \% 201$ luna._djvu.txt

Poe, Edgar Allan. "La incomparable aventura de un tal Hans Pfall". Cuentos 2, traducción de Julio Cortázar, Alianza, 1997, pp. 9-63.

Pratt, Marie Louis. Ojos imperiales. Literatura de viajes y transculturación. Traducción de Ofelia Castillo, Fondo de Cultura Económica, 2010.

Rivas, Manuel Antonio. Syrigias y quadraturas lunares.... Edición de Carmen Fernández Galán, Factoría / Universidad Autónoma de Zacatecas, 2010.

Roas, David. Teorías de lo fantástico. Arco Libros, 2001.

Russen, David. Iter lunare or a vogage to the moon. F. Nutt, 1703. 
Samosata, Luciano de. Historia verdadera. Traducción de Francisco Montes de Oca, Porrúa, 1991.

Schmidt, Siegfred. "La auténtica realidad es que la realidad existe. Modelo constructivista de la realidad, la ficción y la literatura". Teorías de la ficción literaria, compilado por Antonio Garrido Domínguez, Arco/Libros, 1997, pp. 207-238.

Shapin, Sthepen. La revolución cientifica. Una interpretación alternativa. Traducción de José Romo Feito, Paidós, 2000.

Suvin, Darko. Metamorfosis de la ciencia ficción. Sobre la poética y la historia de un género literario. Traducción de Federico Patán López, Fondo de Cultura Económica, 1984.

Todorov, Ttveztan. Introducción a la literatura fantástica. Traducción de Silvia Delpy, Premia, 1981.

Torres Villarroel, Diego. Viaje fantástico del Gran Piscator de Salamanca, edición digital de Clásicos Españoles, Editorial Prometeo, 1931, www.cervantesvirtual.com/obra-visor/viaje-fantasticodel-gran-piscator-de-salamanca--1/html/fee6d9ee-82b1-11dfacc7-002185ce6064_3.html

Tucker, George. A voyage to the moon with some account of the manners and customs, science and philosophy of the people of Morosovia and other lunarians. Forgotten Books, 1827, www.forgottenbooks.com/ en/books/AVoyagetotheMoon_10057256

Vax, Louis. Arte y literatura fantásticas. Editorial Universitaria de Buenos Aires, 1965.

Verne, Julio. De la Tierra a la Luna. Traducción de Ribot y Fontseré, Plaza y Janés, 1998.

Voltaire. Cándido/ Micromegas/ Zadig. Traducción de Elena Diego, Rei, 1991, pp. 173-197.

Wells, H.G. Historias fantásticas. Factoría Ediciones, 2000.

Wilkins, John. "El descubrimiento de un mundo en la Luna". Viajes a la Luna. De la fantasía a la ciencia ficción, de Carlos García Gual, ELR Ediciones, 2005, pp. 85-121. 